\title{
ANALISIS PENGARUH PRODUK GADAI EMAS (RAHN EMAS) TERHADAP PENINGKATAN FEE BASED INCOME (FBI) PADA PT. BANK SYARIAH MANDIRI
}

\author{
ANALYSIS OF THE EFFECT OF GADAI GOLD (RAHN GOLD) \\ PRODUCTS ON INCREASING FEE BASED INCOME (FBI) AT \\ PT. MANDIRI SYARIAH BANK
}

\author{
Ismaulina \\ Fakultas Ekonomi dan Bisnis Islam IAIN Lhokseumawe \\ Jl. Medan-Banda Aceh Km.275 Alue Awe, Muara Dua, Kota Lhokseumawe, Aceh 24352 \\ ismaulina@gmail.com \\ Oumar Tidiane Doumbouya \\ Kullyyah of Economics and Management Sciences IIUM \\ Kuala Lumpur Malaysia \\ doumbouyaoumartidiane@gmail.com
}

Naskah diterima 20 Juli 2020, di-review 03 September 2020, disetujui 31 Desember 2020

\begin{abstract}
Fee Based Income is the income that keeps the company from decreasing the net interest margin (NIM). The amount of profit obtained by the bank as well as being efficient and effective in managing company finances, shows a good bank financial performance. One of the products of PT. BSM that provides Fee Based Income is Gold Pawn (rahn) services provided by banks to customers. This research uses quantitative data. Data obtained from the monthly financial statements of gold pawn products and FBI at PT. Bank Syariah Mandiri period January 2017 - December 2019. This study uses a simple linear regression method. Regression analysis shows that the effect of gold rahn on fee based income is significant where $t_{\text {count }}$ (3.826) $>t_{\text {table }}$ (2.03) and a significance of $0.001<0.05$ so that Ho is rejected and Ha is accepted. It can be concluded that the Gold Rahn variable has a significant effect on FBI. This happens because the total gold Rahn fee received by Bank Syariah Mandiri makes a significant contribution to the bank's profit rate.
\end{abstract}

Keywords: Fee Based Income, Pawn (Rahn) Gold

\begin{abstract}
Abstrak: Pendapatan Fee Based Income merupakan pendapatan yang menjaga perusahaan dari penurunan margin bunga bersih (NIM). Besarnya keuntungan yang diperoleh bank serta efisien dan efektif dalam mengelola keuangan perusahaan, menunjukkan kinerka keuangan bank yang bagus. Salah satu produk produk PT. BSM yang memberikan pendapatan Fee Based Income adalah jasa gadai (rahn) emas yang diberikan bank kepada nasabah. Penelitian ini menggunakan data kuantitatif. Data diperoleh dari laporan keuangan bulanan produk gadai emas dan FBI pada PT. Bank Syariah Mandiri periode Januari 2017 - Desember 2019. Penelitian ini dengan menggunakan metode regresi linier sederhana. Analisis regresi menunjukkan bahwa pengaruh rahn emas terhadap fee based income signifikan dimana thitung $(3,826)>\mathrm{t}$ tabel $(2,03)$ dan signifikansi $0,001<0,05$ sehingga Ho ditolak dan Ha diterima. Maka dapat disimpulkan bahwa _ariable Rahn Emas berpengaruh signifikan terhadap FBI. Hal ini terjadi karena total fee Rahn emas yang diterima oleh Bank Syariah Mandiri memberikan kontribusi yang berarti bagi tingkat keuntungan bank.
\end{abstract}

Kata Kunci: Fee Based Income, Rahn Ema 


\section{PENDAHULUAN}

$\mathcal{F}_{\text {FBI adalah pendapatan yang diterima }}^{\text {ee based income atau disingkat de- ngan }}$ perbankan dari aktivitas kegiatan memberikan jasa-jasa perbankan seperti transfer, kliring, inkaso, safe deposit box, bank card, bank notes, bank guarantees, refrensi bank, bank draft, letter of credit, dan aktivitas penerimaan setoran pembayaran pajak, telepon, air, listrik and uang kuliah. Fee Based Income juga dapat berupa pendapatan dalam melayani pembayaran-pembayaran gaji, dividen, kupon, pemberian bonus/hadiah, transaksi valuta asing dan jasa-jasa lainnya. Adapun biaya yang terdapat dalam FBI antara lain biaya administrasi, biaya kirim, biaya provisi and biaya komisi, biaya sewa serta biaya iuran. Dalam laporan keuangan bank, FBI di kelompok kan kedalam pendapatan operasional lainnya.

Saat ini bank terus berupaya mengoptimalkan Pendapatan FBI. Hal ini dilakukan karena telah terjadi penurunan margin bunga bersih (NIM/ Net Interest Margin) dengan pemangkasan suku bunga acuan. Pada kuartal III/2019 pertumbuhan FBIperbankan semakin membaik, hal ini ditandai dengan data statistik Otoritas jasa Keuangan/OJK, per-September 2019 mencapai $9,52 \%$ secara tahunan (year on year/yoy) menjadi 60,36 trilitun, kenaikan in lebih tinggi dibandingkan tahun2018 pada periode yang sama. Akhirnya sekarang bank sudah banyak mengedepankan pendapatan FBI untuk menjaga perusahaan, dan ini di anggap wajar terkait dengan ketatnya persaingan suku bunga pasca BI menurunkan suku bunga acuan hingga total 100 basis poin (bps), (https://finansial.bisnis. com/read/20191202/90/1176991/bank-mulaigenjot-pendapatan-nonbunga).

Namun FBI perbankan juga memiliki resiko, walaupun resikonya sangat kecil bila dibandingkan dengan pendapatan lainnya. Resiko ini terjadi ketika harga emas turun dan nasabah gagal menebus agunan mereka. PT. BSM termasuk salah satu pemain utama pada bisnis gadai emas. Selain itu PT. BSM telah memiliki dan memperbaiki standar operasional prosedur tentang gadai emas yang sesuai dengan himbauan BI, dimana perbaikan yang dilakukan dalam ratio hutang terhadap nilai barang, pembatasan portfolio gadai emas sebesar $10 \%$ dari total pembiayaan dan berapa kali gadai emas boleh digadaikan kembali (https://edukasi.kompas. com/read/2011/09/19/14181996/perbankan. syariah.siapkan.sop.gadai.emas).

Pada penelitian Kholifa (2012) prosedur dan sistem pemberian pembiayaan produk gadai emas pada Bank Mega Syariah ada 4 prosedur diantaranya prosedur pemberian pembiayaan, pelunasan sebagian pembiayaan, prosedur perpanjangan pembiayaan dan pelelangan jaminan pembiayaan. Keempat prosedur ini telah sesuai dengan surat edaran BI No.14/9/DPbS tanggal 29 februari 2012.

Gadai emas merupakan produk layanan gadai syariah di PT. Bank Syariah Mandiri yang menjadi solusi pemenuhan jangka pendek bagi nasabah yang membutuhkan modal kerja dengan proses yang cepat, mudah dan aman. Ketiga faktor inilah yang menjadikan masyarakat tertarik untuk melakukan transaksi apabila mereka membutuhkan dana cepat dalam jumlah 
yang besar. Ketertarikan terhadap produk gadai emas ini memberikan tren bagi peningkatan keuntungan dan laba perbankan syariah. Hal ini sejalan dengan penelitian (Aprilliya, 2013) yakni semakin tinggi jumlah pembiayaan maka semakin tinggi FBI yang diperoleh Bank. Sehingga FBI dapat dijadikan penompang laba bagi perusahaan perbankan.

Besarnya keuntungan yang di-peroleh bank menunjukkan kinerja keuangan bank yang bagus, benar serta efisien dan efektif dalam mengelola keuangan.

Dari uraian di atas, maka penulis ter- tarik untuk melakukan penelitian bagaimana pengaruh produk gadai emas terhadap peningkatan feebased income. Berdasarkan permasalahan tersebut maka penulis mengangkat masalah pada penulisan ini, yaitu: bagaimana pengaruh produk gadai ( $r a h n$ ) emas terhadap peningkatan fee based income (FBI) pada PT. Bank Syariah Mandiri? Dengan tujuan untuk mengetahui pengaruh produk gadai emas terhadap peningkatan FBI pada PT. PT. Bank Syariah Mandiri.

\section{Kerangka Konseptual}

\section{Pengertian Rahn Emas}

Secara etimologi rahn berarti tetap, kekal dan berkesinambungan. Rahn juga bermakna al-habsu yang berarti menahan atau jaminan. (Al-Zuhaili, 2004). Menurut ulama Syafi'iyah gadai bisa sah dengan dipenuhinya tiga syarat. Per- tama, harus berupa barang, karena utang tidak bisa di gadai kan. Ke dua, penetapan ke pemilikan penggadai atas barang yang di gadaikan tidak terhalang. Ke tiga, barang yang di gadai kan bisa dijual manakala sudah tidak ada masa pelunasan utang gadai, (Antonio, 2001).

Rahn emas adalah gadai yang objek yang digadaikan berupa emas ataupun perhiasan yang memiliki nilai ekonomi, gadai emas juga merupakan salah satu alternatif untuk memperoleh uang tunai dengan cepat. Dalam produk rahn ini, nasabah hanya memberikan barang jaminan berupa emas, dan pihak bank akan mendapatkan imbalan jasa atas penyimpanan dan pemeliharaan barang tersebut. Maka dengan adanya produk rahn emas bank dapat memaksimalkan pendapatan FBI.

Pedoman barang yang boleh di- gadaikan adalah tiap-tiap barang yang boleh dijualbelikan dan mempunyai nilai eko nomis, (Haroen, 2007). Apabila batas waktu pinjaman habis, barang yang digadaikan boleh dijual atau dilelang. (Anshori, 2005).

Taswan menyatakan tentang FBI sebagai berikut:

“Pengelolaan kegiatan operasional bank menuntut selalu dilakukan nya di penjagaan keseimbangan dari pemeliharaan likuiditas dengan kebutuhan profitabilitas yang wajar serta modal yang cukup sesuai dengan penanamnnya. Hal tersebut perlu dilakukan karena bank dalam usaha nya se- lain menanam kan dana dalam aktiva pro- duktif juga memberi kan komitmen jasa-jasa lainnya yang menghasilkan FBI (pendapatan non bunga). (Taswan, 2006).

Sedangkan pengertian FBI menurut Kasmir, (2012) adalah: "FBI adalah keuntungan yang di dapat dari transaksi yang di beri kan dalam jasajasa bank lain nya”. 
Adapun Totok Budisantoso dan Sigit Triandaru (2006) mengemukakan mengenai FBI yaitu: "Dalam rangka menambah sumber-sumber penerimaan bagi bank serta untuk memberikan kepalayanan kepada nasabah nya, bank menyedia kan ber bagai bentuk jasa-jasa. Semakin pesat nya persaingan antar bank mendorong tidak hanya mengandal kan pada sumber penerimaan nya yang utama dari penyaluran kredit me- lainkan dari jasa-jasa yang diberikan pene- rimaan atau income yang berasal dari pem berian jasa-jasa di sebut FBI".

\section{Hubungan Produk Rahn Emas Terhadap FBI}

Menurut Kasmir, pendapatan non bunga (fee based income) adalah keuntungan yang didapat dari transaksi yang diberikan dalam jasa-jasa bank lainnya. Melihat potensi yang sangat besar, oleh karena itu produk gadai (rahn) emas harus bisa menjadi pendapatan yang potensial kepada bank, khususnya bank syariah Mandiri, karena dalam produk rahn emas bank akan memperoleh fee based income atas penyimpanan dan pemeliharaan barang yang digadaikan oleh nasabah, sehingga diperkiraan memiliki hubungan dengan peningkatan fee based income, apabila produk gadai ( $r a h n$ ) emas dan Fee Based Income (FBI) dalam keadaan yang baik, dan sama-sama bertujuan untuk menghasilkan pendapatan bagi perusahaan (Bank), maka disini produk gadai ( $r a h n$ ) emas mempunyai pengaruh terhadap fee based Income.

Hasil Penelitian Aprillya (2013), menyebutkan, bahwa fee based income berpengaruh terhadap ROA dimana besarnya pengaruh FBI sebesar 65,9\% dan

108 | 1smaulina, Oumar Tidiane Doumbouya
$34,1 \%$ sisanya dipengaruhi faktor lain yang tidak diteliti.

Oleh karena itu peneliti berasumsi bahwa produk gadai ( $R a h n$ ) emas berpengaruh terhadap fee based income, dikarenakan fee based income merupakan cerminan dari ROA, dimana antara FBI and ROA memiliki hubungan yang sangat kuat dan me miliki hubungan positif. Hal ini ber- arti di duga bahwa produk gadai (rahn) emas memiliki pengaruh pendapatan fee based income yang akan diperoleh oleh bank yaitu bank mendapatkan fee dari biaya -biaya yang dibebankan kepada nasabah, di antara nya biaya sewa, administrasi, asuran si dan biaya transfer, sehingga dengan biaya tersebut di duga bahwa bank dapat memak- simalkan dan meningkatkan FBI. Hal ini sejalan dengan penelitian yang dilakukan oleh Ismaulina dan Nurul Haqiqi (2018), yang menyebutkan, bahwa peningkatan pembiayaan akan meningkatkan pendapatan fee based income, hal ini terjadi karena peningkatan pendapatan dari biaya administrasi pembiayaan tiap bulannya.

\section{Kerangka Berfikir}

Adapun yang menjadi kerangka pikir dalam penelitian ini adalah:

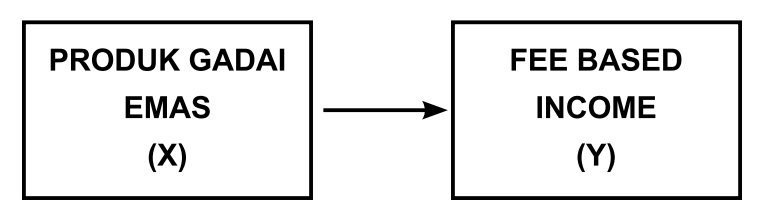

Berdasarkan kerangka teoritis di atas dapat terlihat jelas bahwa peneliti ingin melihat bagaimana pengaruh produk gadai ( $R a h n$ ) emas (variabel X) terhadap pening- katan FBI (variabel Y) pada PT. Bank Syariah Mandiri tahun 
2017-2019. Peneliti menduga bahwa rahn emas berpengaruh signifikan terhadap peningkatan fee based income hal itu disebabkan oleh beberapa hal diantaranya biaya sewa tempat penyimpanan emas yang digadaikan, biaya administrasi yang tetapkan oleh pihak bank untuk pembiyaan rahn, serta biaya transfer saat proses pencairan dana pembiayaan rahn. Semua hal tersebut menjadi indikator variabel peningkatan pendapadan FBI dari produk gadai emas.

\section{METODE PENELITIAN}

Adapun yang menjadi sasaran dalam penelitian ini adalah PT. BSM yang ber sifat Nasional. Dimana data yang ber hubungan dengan PT. BSM dapat di akses melalui situs resmi, www.banksyariahmandiri.co.id. Sedang kan waktu penlitian di lakukan mulai Januari 2017 Desember 2019.

Pada penelitian ini peneliti menggu- nakan jenis penelitian kepustakaan yaitu de ngan bentuk dokumentasi. Sedang kan metode penelitian yang peniliti guna kan yaitu metode penelitian kuantitatif.

Ada pun yang menjadi sumber data dalam penelitian ini adalah data sekunder, berupa laporan bulanan produk gadai emas PT. BSM. Data lain yang berkaitan dengan penelitian di peroleh dari sumber dokumen, dan arsip dari PT. BSM, buku-buku, majalah, surat kabar yang berkaitan dengan topik data yang akan di teliti serta datadata yang tersedia di internet and serta jurnal yang bersangkutan dengan judul penelitian.

Adapun teknik pengumpulan data yang diguna kan peneliti dalam penelitian ini adalah data yang berasal dari dokumenta si. Dalam penelitian ini dokumentasi yang di gunakan adalah laporan bulanan produk gadai emas pada PT. Bank Syariah Mandiri dari Januari 2017Desember 2019.

Metode pengolahan data diproses dengan menggunakan perangkat lunak yaitu dengan program SPSS (Statistic Package for Special Sciences) dengan pertimbangan kecepatan dan keakuratan proses. Adapun uji yang dilakukan melalui program SPSS yaitu uji normalitas, Uji Koefisien Determinasi $\left(\mathrm{R}^{2}\right)$, serta Uji t (parsial).

\section{PEMBAHASAN DAN HASIL}

\section{Perkembangan Rahn dari PT. BSM}

Rahn Emas merupakan salah satu produk yang ditawarkan oleh PT Bank Syariah Mandiri di mana bank memperoleh fee dari produk tersebut. Perkembangan jumlah fee yang didapatkan pada produk rahn emas yang di himpun oleh PT BSM pada p e r iode Januari 2017 sampai dengan Desember 2019 dapat kita lihat pada grafik sebagai berikut: 
Gambar 1

Grafik Perkembangan Rahn Emas Pada PT. BSM Periode 2017-2019

GadaiEmas

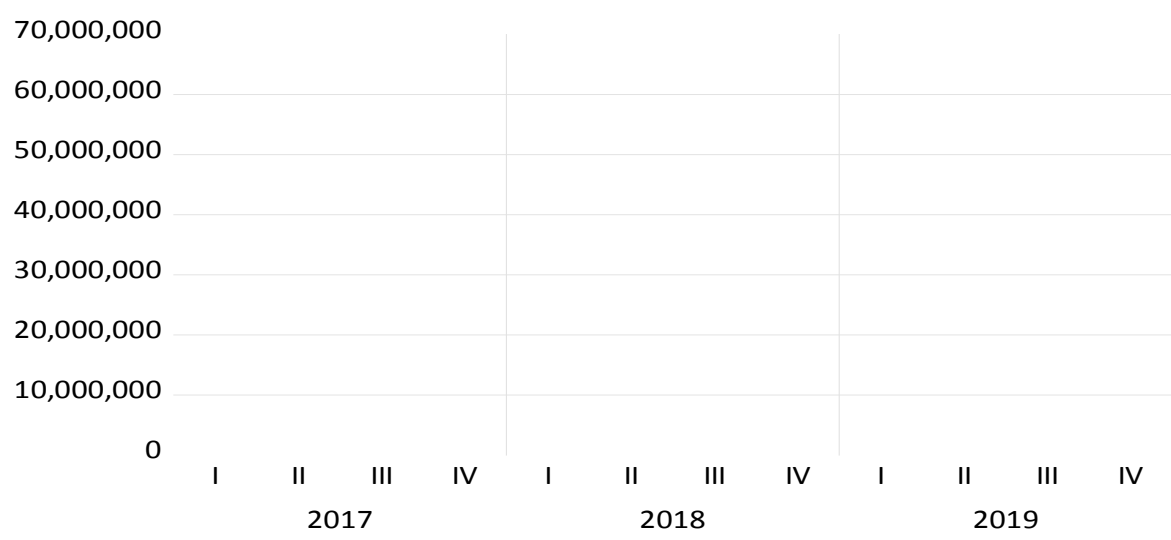

Berdasar kan gambar 1 diatas ter- lihat lainnya. Jasa-jasa pendukung ini diberikan bahwa total rahn emas bergerak se cara fluktuatif untuk mendukung dan mem perlancar kegiatan yaitu adakalanya naik dan adakala nya turun, menghimpun dana dan menyalurkan dana, baik hal ini ter bukti total rahn emas terendah yang yang berhubung- an langsung dengan kegiatan diterima oleh PT. BSM pada Maret 2017 yaitu simpanan dan kredit maupun tidak langsung. senilai Rp.8.928.842. sedang kan total rahn emas ter tinggi yang di terima oleh PT. BSM pada Desember 2017 yaitu senilai Rp. 65.532.472.

Di mana bank akan mendapatkan FBI dari

\section{Perkembangan FBI Pada PT. BSM}

FBI adalah keuntungan yang di dapat dari transaksi yang diberikan dalam jasa-jasa bank

Gambar 2

Grafik Perkembangan FBI Pada PT. BSM Periode 2017-2019

FBI

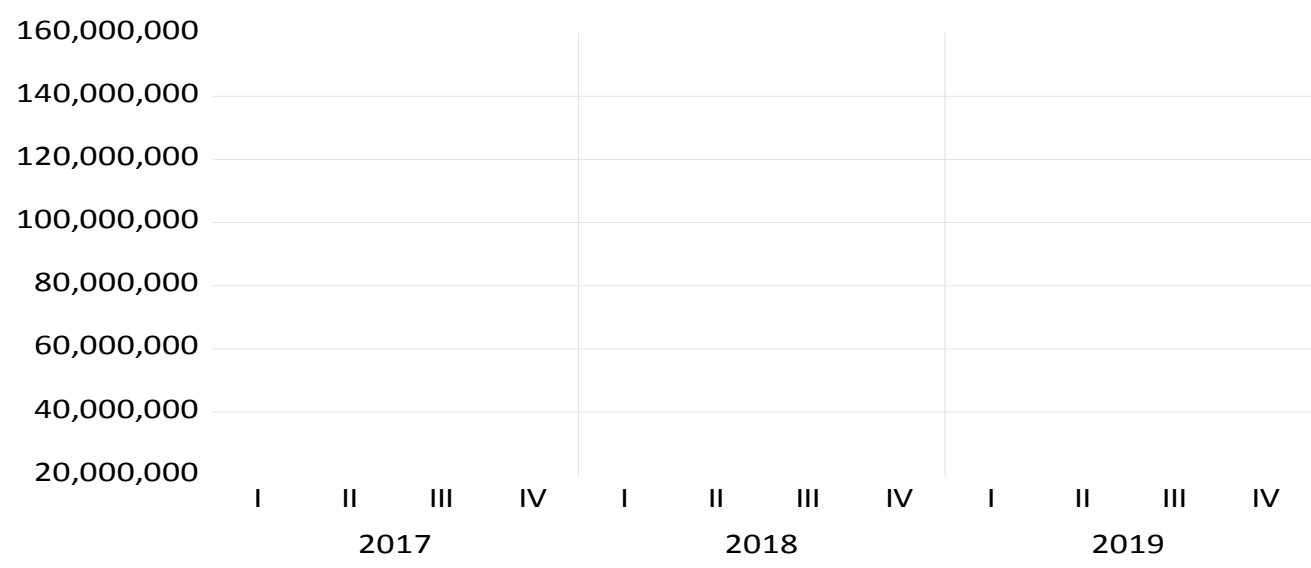

110 | 1smaulina, Oumar Tidiane Doumbouya 
Berdasar kan gambar 2 diatas terlihat bahwa total FBI bergerak secara fluktuatif yaitu adakalanya naik dan adakala nya turun, hal ini terbukti total FBI terendah yang diterima oleh PT. Bank Syariah Mandiri pada Desember 2019 yaitu senilai Rp. 24.970.828. sedangkan total FBI tertinggi yang diterima oleh PT. Bank Syariah Mandiri pada Januari 2017 yaitu senilai Rp. 145.360.104.

\section{Deskripsi Statistik}

Deskripsi statistik digunakan untuk menggambarkan atau mendeskripsikan data masing-masing variabel yang telah diolah. Hasil peng- olahan data dalam bentuk deskripsi statistik akan menampilkan karak ter sampel yang digunakan dalam penelitian yang meliputi jumlah sampel $(\mathrm{N})$, nilai mean, nilai maksimum, minumum, standar deviasi. Adapun hasil pengolahan data metode deskripsi statistik dengan bantu eview 10 yaitu sebagai berikut:

Tabel 1

Deskripsi Statistik

\begin{tabular}{|l|l|l|}
\hline & \multicolumn{1}{|c|}{ FBI } & \multicolumn{1}{|c|}{ GADAI EMAS } \\
\hline Mean & 91897108 & 18997092 \\
Median & 94339149 & 15061030 \\
Maximum & 145360104 & 65532472 \\
Minimum & 24970828 & 8928842. \\
Std. Dev. & 20057307 & 12889016 \\
Skewness & -0.601282 & 2.436744 \\
Kurtosis & 5.703431 & 8.011317 \\
Jarque-Bera & 13.13204 & 73.29626 \\
Probability & 0.001407 & 0.000000 \\
Sum & $3.31 \mathrm{E}+09$ & $6.84 \mathrm{E}+08$ \\
Sum Sq. Dev. & $1.41 \mathrm{E}+16$ & $5.81 \mathrm{E}+15$ \\
Observations & 36 & 36 \\
\hline
\end{tabular}

Berdasarkan tabel di atas menun- jukkan bahwa terdapat 36 data yang diguna kan dalam penelitian ini yang meliputi varia bel FBI dan variabel Rahn. Pada variabel FBI memiliki nilai standar devisiasi yang lebih kecil dibandingan dengan nilai rata-rata nya yaitu 91.897.108 < 20.057.307 Begitu pula dengan variabel rahn juga memiliki nilai standar devisiasi yang lebih kecil dibandingan dengan nilai rata-rata nya yaitu 18.997.092 < 12.889.016 Yang berarti bahwa data variabel FBI dan rahn memiliki tingkat probabilitas yang baik. Namun, apabila nilai rata-rata (mean) masing-masing variabel lebih kecil dari pada nilai standar devisiasi, biasanya di dalam data tersebut terdapat outller (data yang terlalu ekstrim). Data outller tersebut biasanya akan menyebabkan tidak normalnya distribusi data. Berdasarkan hasil uji statistik deskripsi di atas dapat disimpulkan bahwa tidak terdapat data yang outller.

Dari tabel di atas juga menjelaskan bahwa nilai maksimum dari variabel FBI adalah 145.360.104 dengan nilai terendahnya yaitu 24.970.828. Sedangkan untuk variabel rahn memiliki nilai tertinggi yaitu 65.532.472 dan nilai terendahnya adalah 8.928.842. Maka dapat disimpulkan bahwa 
nilai maksimum dari kedua variabel FBI dan rahn yaitu 145.360.104 sedangkan nilai terendah dari kedua variabel tersebut adalah 8.928.842 yang merupakan nilai tertinggi dan terendah dari variabel FBI.

\section{Uji Normalitas}

Uji normalitas digunakan untuk meli- hat apakah nilai residual ter distribusi nor- mal or tidak. Model regresi yang baik adalah memiliki nilai residual yang terdis- tribusi normal. Jika nilai probabilitas nya (nilai sig) > 0,05 maka H-null tidak di tolak namun apabila nilai probabilitas nya (nilai sig) < 0,05 maka H-null ter tolak. Adapun hasil pengujian norma litas data dalam penelitian ini adalah sebagai berikut:

Tabel 2

Uji Normalitas

One-Sample Kolmogorov-Smirnov Test

\begin{tabular}{|ll|r||}
\hline \multicolumn{2}{|c|}{} & \multicolumn{1}{|c|}{ Unstandardized Residual } \\
\hline $\mathrm{N}$ & & 36 \\
Normal Parameters ${ }^{\mathrm{a}, \mathrm{b}}$ & Mean &, 0000000 \\
& Std. Deviation & 159160222,88953033 \\
Most Extreme Differences & Absolute &, 085 \\
& Positive &, 072 \\
& Negative &,- 085 \\
Test Statistic & &, 085 \\
Asymp. Sig. (2-tailed) & &, $200^{\mathrm{c}, \mathrm{d}}$ \\
\hline
\end{tabular}

a. Test distribution is Normal.

b. Calculated from data.

c. Lilliefors Significance Correction.

d. This is a lower bound of the true significance.

Dari hasil uji kolmogorov (K-S test) di atas di ketahui bahwa nilai asym potic signifi cant (two tailed) sebesar 0,200. Nilai ini lebih besar dari $\propto=0,05$. Jadi hasil ter sebut menjelaskan bahwa pernyataan H-null tidak di tolak. Maka dapat di simpulkan bahwa data terdistribusi normal.

Untuk melihat apakah data yang diteliti terdistribusi normal dengan mengamati langsung dari grafik atau histogram hasil dari uji SPSS dengan ketentuan sebagai berikut:
1. Jika data yang menyebar mengikuti garis diagonal pada grafik maka distribusi data dalam penelitian ini menunjukkan normal.

2. Jika sebaliknya, data yang menyebar tidak mengikuti garis diagonal pada grafik maka distribusi data dalam penelitian ini tidak normal.

112 | Ismaulina, Oumar Tidiane Doumbouya 
Gambar 3

Grafik Normal P-Plot

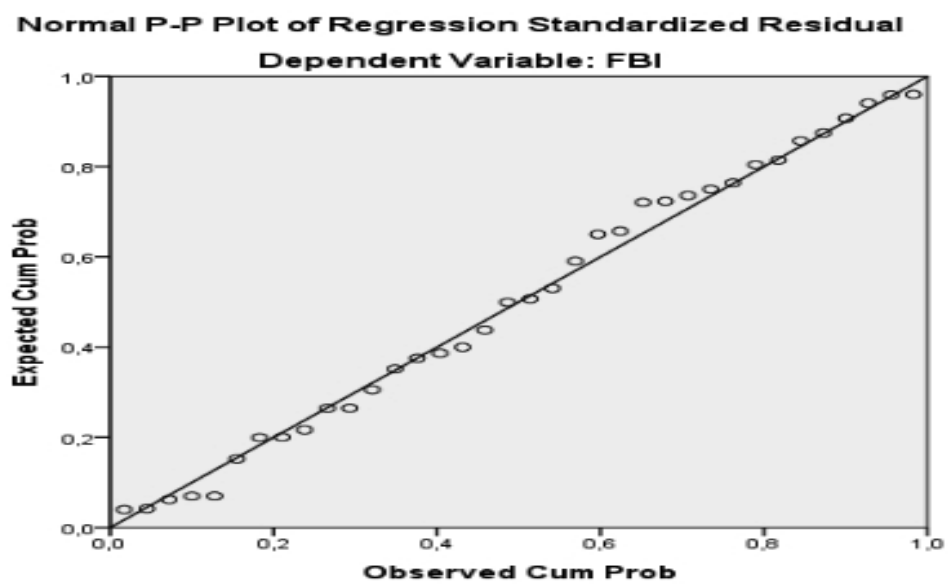

Dari grafik Normal (P-Plot) di atas di ketahui Koefisien Determinasi bahwa data dalam penelitian ini menyebar mengikuti garis diagonal pada grafik. Maka dapat disimpul kan bahwa data ter distribusi normal.

Berikut ini tabel hasil perhitungan ko- efisien deter minasi (R-Squared):

Tabel 3

Hasil Perhitungan Koefisien Determinasi

Model Summary

\begin{tabular}{|l|l||l|l|l|}
\hline Model & R & R Square & Adjusted R Square & Std. Error of the Estimate \\
\hline \hline 1 &, $549^{\mathrm{a}}$ &, 301 &, 280 & 16498873,98373 \\
\hline
\end{tabular}

a. Predictors: (Constant), Rahn Emas

Berdasarkan hasil perhitungan regresi linear sederhana menggunakan SPSS diperoleh koefisien determinasi $\left(\mathrm{R}^{2}\right)$ sebesar 0,301. Artinya 30,1\% tingkat probabilitas (FBI) dipengaruhi oleh variabel bebas rahn. Hal Ini terjadi karena produk gadai emas dalam menghasilkan FBI hanya terdiri dari tiga indikator yaitu biaya sewa tempat emas yang digadai atau safedeposit box, biaya administrasi yang ditetapkan bank dan biaya transfer saat proses pencairan dana pembiayaan. Sementara masih banyak lagi produk yang dapat meningkatkan pendapatan FBI, seperti yang telah disebutkan pada bagian pendahuluan. Sedangkan $69,9 \%$ sisanya di pengaruhi oleh faktor-faktor lain di luar model.

\section{Hasil Persamaan Regresi Linear Sederhana}

Regresi linear sederhana adalah hubu ngan antara suatu variabel X dan Y. Analisis ini diguna kan untuk me ngetahui hubungan antara variabel $\mathrm{X}$ dan $\mathrm{Y}$ apa kah arah nya positif ataupun negative. Dengan menggunakan metode regresi seder hana dan pengolahan dibantu dengan SPSS, maka hasil perhitungannya adalah: 
Tabel 4

Hasil Regresi Linear Sederhana

Coefficients $^{\mathrm{a}}$

\begin{tabular}{|c|c|c|c|c|c|}
\hline \multirow[b]{2}{*}{ Model } & \multicolumn{2}{|c|}{ Unstandardized Coefficients } & \multirow{2}{*}{$\frac{\begin{array}{c}\text { Standardized } \\
\text { Coefficients }\end{array}}{\text { Beta }}$} & \multirow[b]{2}{*}{$\mathbf{t}$} & \multirow[b]{2}{*}{ Sig. } \\
\hline & B & Std. Error & & & \\
\hline $\begin{array}{l}\mathbf{1} \\
\text { (Constant) } \\
\text { Rahn Emas }\end{array}$ & $\begin{array}{l}78.993 .455,826 \\
, 828\end{array}$ & $\begin{array}{l}\text { 4.945.415,386 } \\
, 216\end{array}$ &, 549 & $\begin{array}{l}15,973 \\
3,826\end{array}$ & $\begin{array}{l}, 000 \\
, 001\end{array}$ \\
\hline
\end{tabular}

a. Dependent Variable: FBI

Berdasarkan tabel diatas maka dapat disimpul kan bahwa variabel gadai ( $r a h n$ ) emas (X) ber pengaruh signifikan ter hadap peningkatan FBI (Y) pada BSM. Hal ini dapat dilihat dari pro babilitas untuk variabel rahn emas sebesar 0,001 yang ber nilai di bawah 0,05. Adapun persamaan dari regresi linier sederhana adalah yaitu sebagai berikut:

$Y^{\prime}=\alpha+b X=78.993 .455,826+0,828 X$

\section{Pengertian:}

1. Nilai konstanta (Y) sebesar 78.993.455,826 artinya jika variabel rahn emas (X) konstan pada nol, maka variabel FBI (Y) tetap sebesar 78.993.455,826.

2. Nilai koefisien regresi X (rahn emas) dari perhitungan regresi sederhana didapat hasil koefisien b sama dengan 0,828. Ini menunjukkan bahwa setiap ada satu peningkatan rahn emas (X) maka fee based income (FBI) juga akan mengalami peningkatan sebesar $82,8 \%$.

\section{Uji T}

Uji t-test digunakan untuk menge- tahui pengaruh variabel-variabel bebas terhadap variabel terikat. Nilai $t_{\text {tabel }}$ diper oleh dengan cara menentukan $\mathrm{df}$ dengan rumus $\mathrm{df}=\mathrm{n}-\mathrm{k}$ dan $\alpha=\frac{0,05}{2}$ $=0,025$ maka $\mathrm{df}=36-2=34$, sehingga diperoleh $114 \mid$ Ismaulina, Oumar Tidiane Doumbouya nilai $_{\text {tabel }}$ sebesar 2,03. Sedang kan hasil uji t hitung dengan menggunakan SPSS adalah sebagai mana yang terdapat dalam tabel 4.6 di samping, dan dapat disimpulkan pengaruh Rahn Emas terhadap FBI signifikan dimana nilai $t_{\text {hitung }}(3,826)>t_{\text {tabel }}$ $(2,03)$ dan signifikansi se- besar 0,001<0,05, sehingga $\mathrm{H}$-null di tolak dan $\mathrm{H}$-alternatif di terima. Maka dapat disimpulkan bahwa variabel rahn emas berpengaruh dan signifikan terhadap FBI.

\section{PENUTUP}

\section{Kesimpulan}

Berdasar kan hasil analisis dan pembahasan yang telah dijelaskan di bab ter dahulu, maka kesimpulan yang diperoleh dari pene- litian ini adalah hasil analisis regresi menun jukkan bahwa pengaruh rahn emas ter hadap FBI signifikan dimana dengan nilai $t_{\text {hitung }}(3,826)>t_{\text {tabel }}(2,03)$ dan signifikansi sebesar 0,001<0,05, sehingga H-null ditolak dan $\mathrm{H}$-alternatif diterima. Maka dapat disimpulkan bahwa variabel rahn emas berpengaruh dan signifikan secara parsial ter hadap variabel FBI. Hal ini terjadi dikarenakan total fee rahn emas yang diterima oleh BSM memberikan kon-tribusi yang berarti bagi tingkat keuntungan bank. 
VOLUME 4, NOMOR 2, DESEMBER 2020

\section{Saran}

Adapun saran yang dapat peneliti ajukan adalah sebagai berikut :

Bagi pihak perbankan syariah khusus- nya PT. Bank Syariah Mandiri agar menerap kan strategistrategi tertentu dalam memasarkan produk rahn emas agar jauh lebih menonjol dari produk rahn emas yang ditawarkan oleh instansi lainnya sehingga masyarakat akan memilih menggunakan produk rahn emas yang ada pada BSM sehingga fee yang diterima dari rahn emas pun dapat meningkat hingga dapat berkon- tribusi secara efisien dalam peningkatan FBI pada Bank Syariah Mandiri.

Untuk peneliti selanjutnya agar tidak hanya mengaju pada satu data dari laporan bulan pada suatu perbankan syariah saja, namun data yang digunakan dalam penelitian mengaju pada lebih dari satu perbankan syariah sehingga dapat dibandingkan antara bank-bank syariah tersebut. Sehingga pihak-pihak yang membaca penelitian tersebut mengetahui mana Bank syariah yang memiliki kinerja yang baik.

\section{DAFTAR KEPUSTAKAAN}

Al-Zuhaili, Wahbah. 2004. Al-fiqh al-Islami wa adillatuhu - juz 6. Jakarta: Dar Fikr al-Mu'asir.

Anshori, Abdul Ghofur. 2005. Gadai Syariah di Indonesia: Konsep Implementasi dan Institusional, Cet 1. Yogyakarta: Gadjah Mada University Press. Antonio, Muhammad Syafi'i. 2001. Bank Syariah, Wacana Ulama dan Cendikiawan. Jakarta: Bank Indonesia dan Tazkia Institute.
Aprillya, Shella Fitri. 2013. Pengaruh Fee Based Income Terhadap Tingkat Return On Assets (ROA) (Studi Pada Perbankan Bumn Yang Terdaftar Di Bursa Efek Indonesia), Bandung: Fakultas Ekonomi universitas Pasundan.

Haroen, Nasrun. 2007. Fiqh Muamalah Cet. Ke-2. Jakarta: Gaya Media Pratama.

Ismaulina, I., \& Haqiqi, N. 2018. Pengaruh DPK dan Pembiayaan terhadap Peningkatan FEE BASED INCOME PT. BANK SYARIAH MANDIRI. Jurnal Ekonomi Syariah, Akuntansi dan Perbankan (JESKaPe), Vol. 2, No. 1, 2018.

Kasmir. 2012. Bank dan Lembaga Keuangan, Cet 2. Jakarta: Rajawali Pers.

Khairunnisa, Arindita. 2014. Analisis Laba Kontibusi Produk Pembiayaan Dan Fee Based Income Pada Bank Syariah Mandiri Cabang Depok, Depok: Universitas Gunadarma, 2014.

Kholifah, Nadifatul. 2012. Analisis Sistem dan Prosedur Gadai Emas Syariah Pada PT. Bank Mega Syariah Kantor Cabang Malang (Jurnal Program Studi Ilmu Administrasi Malang Universitas Brawijaya. Malang, 2012.

Taswan. 2006. Manajemen Perbankan, Cet 1. Yogyakarta: YKPN.

Totok, Budisantoso, dkk. 2006. Bank dan Lembaga Keuangan Lain, (Jakarta: Salemba Empat. 